TABLE 1. Summary of arterial blood gases and noninvasive ventilatory parameters before and during extracorporeal support with the Hemolung (ALung Technologies, Pittsburgh, Pa)

\begin{tabular}{|c|c|c|c|c|c|}
\hline & \multirow[b]{2}{*}{ On admission to ICU } & \multicolumn{4}{|c|}{ During Hemolung therapy } \\
\hline & & Hour 2 & Hour 24 & Hour 48 & Hour 132 (weaning) \\
\hline $\mathrm{pH}$ & 7.23 & 7.34 & 7.40 & 7.40 & 7.38 \\
\hline $\mathrm{PaCO}_{2}$ (torr) & 90 & 67.4 & 61.7 & 55.9 & 56.2 \\
\hline Peak inspiratory pressure $(\mathrm{mm} \mathrm{Hg})$ & - & 20 & 20 & 20 & 20 \\
\hline Peek expiratory pressure (mm Hg) & - & 6 & 5 & 5 & 5 \\
\hline $\mathrm{FIO}_{2}$ & - & - & $26 \%$ & $32 \%$ & $28 \%$ \\
\hline Respiratory rate & $30-40$ & 18 & 16 & 13 & 14 \\
\hline Minute ventilation & - & 8.0 & 6.4 & 4.8 & 8.7 \\
\hline
\end{tabular}

$\mathrm{ICU}$, Intensive care unit; $\mathrm{PaCO}_{2}$, arterial carbon dioxide tension; $\mathrm{FlO}_{2}$, inspired oxygen fraction. Data from Burki and colleagues. ${ }^{6}$

After titrating the heparin dosage, the bleeding ceased within 2 hours and did not reappear; no transfusion was necessary. There were no other complications during or after extracorporeal support. Plasma-free hemoglobin levels remained below the baseline measurement of $6.5 \mathrm{mg} / \mathrm{dL}$. Platelet counts decreased over the course of extracorporeal therapy as expected without serious effects.

During treatment with the Hemolung, the patient was given a high-urgent status for the transplant waiting list. The patient successfully received a bilateral lung transplant 31 days after Hemolung support and was discharged 63 days post-transplant.

\section{CONCLUSIONS}

The risk of bleeding is present with any form of extracorporeal support, including hemodialysis. The alternative to EC$\mathrm{CO}_{2} \mathrm{R}$ therapy would have been IMV, which is associated with different but more serious risks, as well as significantly greater patient discomfort and quality of life. Compared with ECMO systems used for full respiratory or cardiopulmonary support, the Hemolung was substantially simpler to operate.
Oxygen demand was met by NIV support with positive end airway pressures and supplemental oxygen.

The authors thank Dr Gerhard Weinreich (Ruhrlandklinik) for assistance in data collection and analysis, and Alethea Wieland and Tracey Dill (ALung Technologies) for support in data assembly and validation.

\section{References}

1. Schonhofer B, Euteneuer S, Nava S, Suchi S, Kohler D. Survival of mechanically ventilated patients admitted to a specialised weaning centre. Intensive Care Med. 2002;28:908-16.

2. Chandra D, Stamm JA, Taylor B, et al. Outcomes of non-invasive ventilation for acute exacerbations of COPD in the United States, 1998-2008. Am J Respir Crit Care Med. 2012;185:152-9.

3. Smits JM, Mertens BJ, Van Houwelingen HC, Haverich A, Persijn GG, Laufer G. Predictors of lung transplant survival in eurotransplant. Am J Transplant. 2003;3:1400-6.

4. Batchinsky AI, Jordan BS, Regn D, et al. Respiratory dialysis: reduction in dependence on mechanical ventilation by venovenous extracorporeal $\mathrm{CO} 2$ removal. Crit Care Med. 2011;39:1382-7.

5. Wearden PD, Federspiel WJ, Morley SW, et al. Respiratory dialysis with an activemixing extracorporeal carbon dioxide removal system in a chronic sheep study. Intensive Care Med. 2012;38:1705-11.

6. Burki NK, Mani RK, Herth FF, et al. A novel extracorporeal CO2 removal system: results of a pilot study in COPD patients with hypercapnic respiratory failure. Chest. 2013;143:678-86.

\title{
Swyer-James-MacLeod syndrome with renal ectopy misdiagnosed as pneumothorax and chest tube drained: Case study
} \footnotetext{
Amasya, Ağrı, and Ankara, Turkey

From the Faculty of Medicine, ${ }^{a}$ Thoracic Surgery Department, Bozok University, Yozgat, Turkey; Special Amasya Experts Medical Center, ${ }^{\mathrm{b}}$ Chest Diseases Unit, Amasya, Turkey; Thoracic Surgery Department, ${ }^{\mathrm{c}}$ Ağrı State Hospital, Ağrı, Turkey; and Faculty of Medicine, ${ }^{\mathrm{d}}$ Thoracic Surgery Department, Gazi University, Ankara, Turkey.

Disclosures: Authors have nothing to disclose with regard to commercial support.

Received for publication Dec 6, 2012; accepted for publication Jan 17, 2013; available ahead of print Feb 18, 2013.

Address for reprints: Bayram Metin, MD, Thoracic Surgery Department, Bozok Undivert, Faculty of Medicine, 66000 Yozgat, Yozgat, Turkey (E-mail: drbaymet@ hotmail.com).

J Thorac Cardiovasc Surg 2013;145:e44-7

$0022-5223 / \$ 36.00$

Copyright (c) 2013 by The American Association for Thoracic Surgery

http://dx.doi.org/10.1016/j.jtcvs.2013.01.035
}

Bayram Metin, MD, ${ }^{\mathrm{a}}$ Emre Özkan, MD, ${ }^{\mathrm{b}}$ Murat Sariçam, MD,${ }^{\mathrm{c}}$ and Olgun Kadir Ariba, MD, ${ }^{\mathrm{d}}$ Yozgat
Swyer-James-MacLeod syndrome is characterized by hyperlucency caused by an increase in aeration and a decrease in vascularity in a lung lobe. The syndrome usually develops as a result of recurrent pulmonary infections in childhood and should be discriminated from pneumothorax and other diseases causing unilateral hyperlucency on chest radiography. We present a patient with a diagnosis of Swyer-James-MacLeod syndrome with a renal anomaly who received a mistaken diagnosis of pneumothorax and had a chest tube inserted. 


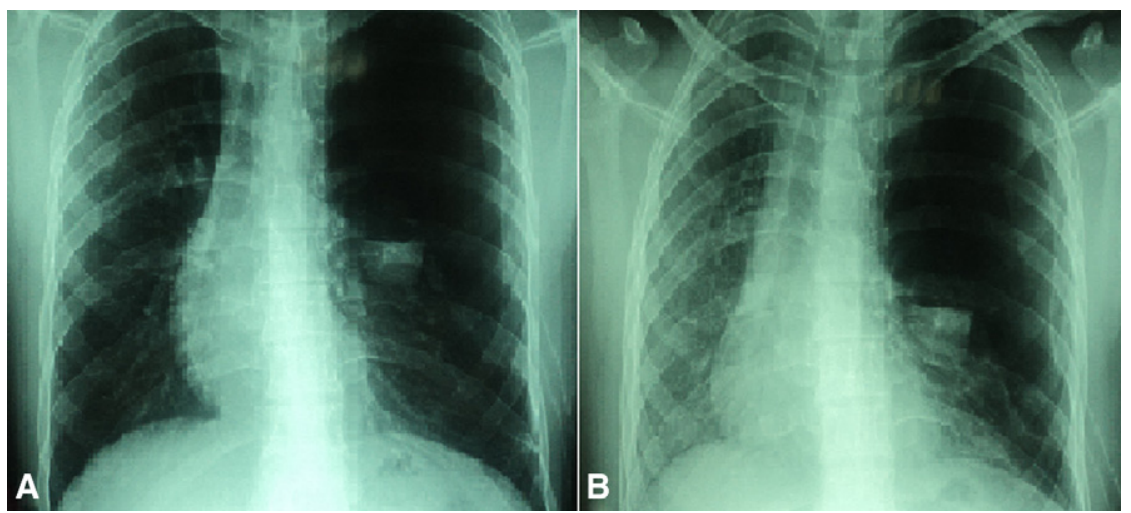

FIGURE 1. A, Inspiratory phase. B, Expiratory phase; air trapping in the upper lobe of the left lung is shown.

The disease was first reported in a 6-year-old boy in 1953 by Swyer and James and then diagnosed in 9 patients who had unilateral hyperlucency on chest radiography 1 year later by MacLeod. Later, this disease was identified as "SwyerJames-MacLeod syndrome." ${ }^{, 2}$ Although many procedures, such as computed tomography (CT), bronchography, angiography, and scintigraphy, are helpful in the diagnosis, Swyer-James-MacLeod syndrome can be simply diagnosed by chest radiography performed during the inspiratory and expiratory phases. ${ }^{3}$ On radiology, this syndrome shows pulmonary artery abnormalities (eg, pulmonary embolism, endobronchial foreign bodies, and lesions) and diseases causing hyperaeration (eg, unilateral bullous disease and pneumothorax). ${ }^{4,5}$

\section{CLINICAL SUMMARY}

A 21-year-old man was referred to our clinics with symptoms of chest pain and dyspnea. After tube thoracostomy was applied for the left pneumothorax before the diagnosis, he was referred to our clinics. The patient's medical history stated that he had used antibiotics several times for pneumonia before the diagnosis. There was no tuberculosis in his family history. The patient had a 5-pack per year smoking history. He had no foreign body aspiration. He also added that he was told previously by doctors that his kidneys were in abnormal anatomic positions. On physical examination, both of the hemithoraces were equally meeting respiration, breath sounds decreased in the left upper zone by auscultation, and crepitant rales were heard at the end of inspiration in that

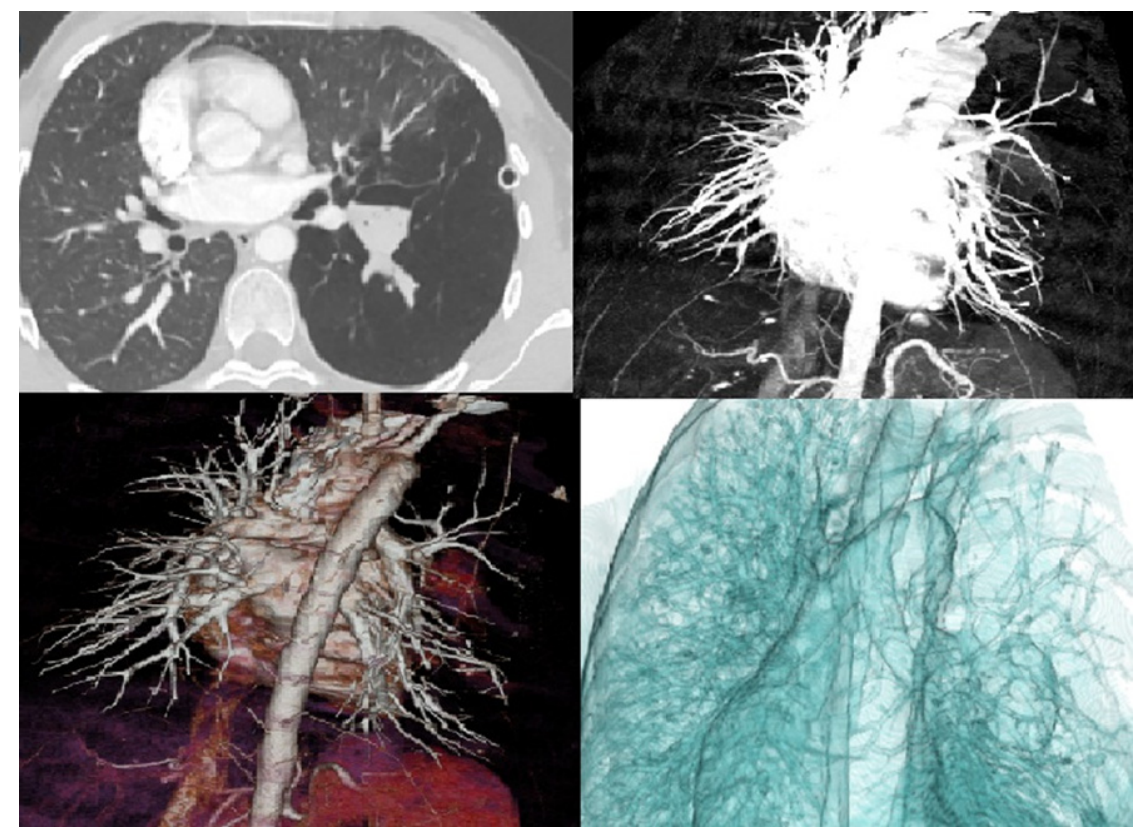

FIGURE 2. Hyperaeration, bronchiectasic field, and decrease in vascularity in the upper lobe of the left lung are shown on 3-dimensional pulmonary $\mathrm{CT}$ angiography. $C T$, Computed tomography. 


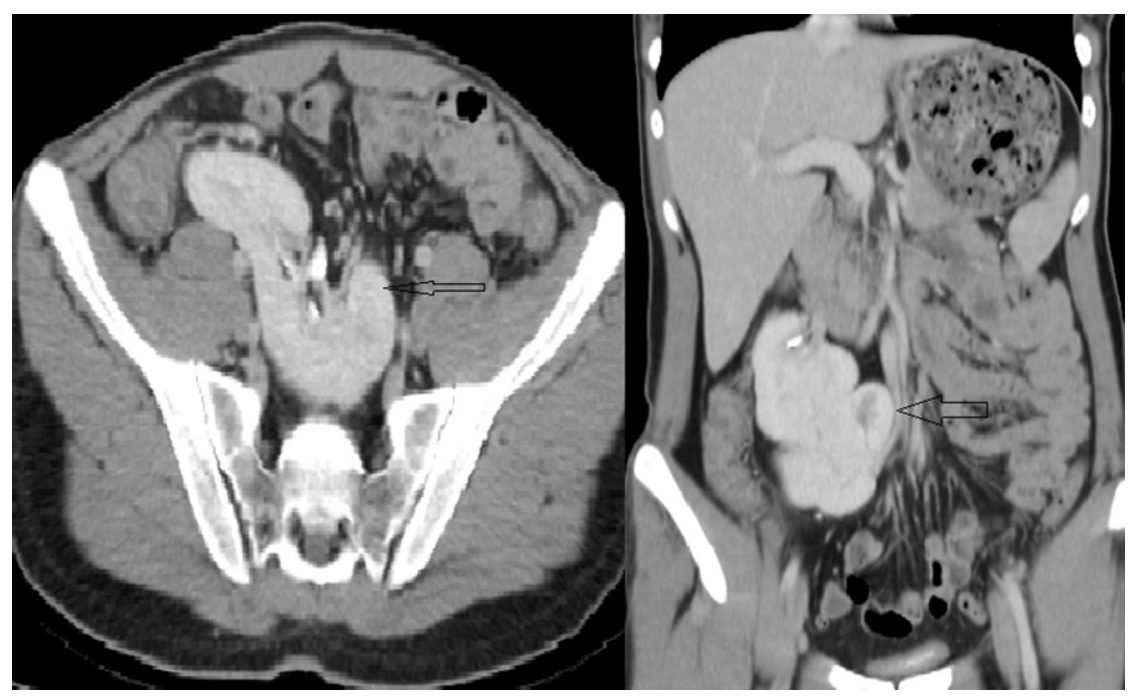

FIGURE 3. Renal ectopy and fusion anomaly are shown on abdominal CT. CT, Computed tomography.

region. Hemoglobin $(16.3 \mathrm{~g} / \mathrm{d})$, white blood cell count (8700/ $\mathrm{mm}^{3}$ ), platelets $\left(230.000 / \mathrm{mm}^{3}\right)$, and biochemical measurements were normal. The respiratory function test values were as follows: forced expiratory volume in 1 second 2.65 $(60 \%)$, forced vital capacity $2.89(55 \%)$, forced expiratory volume in 1 second/forced vital capacity 92 , peak expiratory flow 82, and positive reversibility test (14\%). Arterial blood gas testing showed normal levels $\mathrm{pH} 7.46$, oxygen tension 93, carbon dioxide tension 35 , bicarbonate 24.5 , oxygen saturation 97.7). Cardiac spaces were normal, pulmonary artery pressure was $20 \mathrm{~mm} \mathrm{Hg}$, and ejection fraction was $65 \%$ on transthoracic echocardiography. On chest radiography, there was air trapping in the expiratory phase in the left hemithorax (Figure 1). On triphasic pulmonary CT angiography, there was hyperaeration, hypovascularization, and a cystic bronchiectasic field in the left upper lobe (Figure 2). Bronchoscopy was performed to exclude a lesion or foreign body that may cause endobronchial obstruction, and the result was normal. The abdominal CT showed that both of the kidneys were ectopically fused through the inside pelvis and located in the right paramedian line below the umbilicus (Figure 3). We determined that the patient was misdiagnosed with pneumothorax after clinical and radiologic evaluation, and a chest tube was inappropriately inserted. The patient had Swyer-James-MacLeod syndrome with left upper lobe hyperlucency. After the chest tube was removed and influenza and pneumococcus vaccines were injected, he was discharged from the hospital and taken to outpatient follow-up.

\section{DISCUSSION}

Swyer-James-MacLeod syndrome pathogenesis is generally accepted as originating from bronchiolitis obliterans developing from infections during childhood. Bronchiolitis obliterans is primarily caused by pathogens, such as measles, whooping cough, tuberculosis, mycoplasma pneumonia, influenza A, and adenovirus type 3,7 , and $21 .^{4}$ Air trapping and damage form as the result of obstruction in the bronchioles and alveoli due to acute bronchiolitis caused by these pathogens. Diverse bronchiectasis types can be seen frequently as a result of destruction occurring in the bronchi. Alveoli cannot complete normal formation, and pulmonary vascularity cannot develop adequately. As a result, hyperaeration, hypovascularization, and bronchiectasic changes are observed on radiography of the affected side because of decreased vascularity and air trapping. ${ }^{4,6}$

Patients generally present with the symptoms of cough, dyspnea, dyspnea with effort, chest pain, and sometimes hemoptysis according to the level of bronchiectasis. ${ }^{4}$ Our patient presented to the hospital with the symptoms of chest pain and dyspnea. He was misdiagnosed with pneumothorax and treated unnecessarily with a surgical procedure because of the hyperaeration and insufficient vascularity on the affected side shown on radiography. ${ }^{4}$ For this reason, the surgical procedure should be performed after $\mathrm{CT}$ evaluation and consultation with chest surgeons in suspicious cases.

A localized hyperlucent image and decrease in perfusion in a lobe or segment are detected on classic radiologic findings. A smaller hilus and decreased vascularity are observed on the affected side. The detection of a permanent hyperlucent view caused by air trapping in the end-expiratory phase on radiography is an important finding. Bronchiectasic changes also can be seen clearly on radiography. ${ }^{3}$ When we compared the radiographs taken in the inspiratory and expiratory phases, air trapping in the expirium, shifting of the mediastinum to the normal side, and the presence of a bronchiectasic field in the affected side were observed in this patient.

A unilateral or bilateral hyperlucent and hypovascular view can be shown more clearly on CT. In addition, detection of a permanent hyperlucent view due to air trapping in the affected lung tissue in the end-expiratory phase on CT is 
an essential finding. The bronchiectasic field and nature also can be seen in a more detailed pattern on CT. The decrease in pulmonary vasculature can be demonstrated demographically by using 3-dimensional CT angiographic reformatted images, as done in the presented case. ${ }^{3,7}$

Additional anomalies may be found in Swyer-JamesMacLeod syndrome. Patent ductus arteriosus has been reported. ${ }^{8}$ Bilateral involvement and hypoplasia in the other lobe were also reported by Yildiz and colleagues. ${ }^{9}$ Renal ectopic fusion anomaly was incidentally detected in our case. Pulmonary hypoplasia, ventricular septal defect, pulmonary hypertension, mental retardation, and skeletal deformities have been reported with fusion and ectopic anomalies of the kidney, ${ }^{10,11}$ but a renal anomaly with Swyer-JamesMacLeod syndrome has not been reported in the literature.

\section{CONCLUSIONS}

We present this case of Swyer-James-MacLeod syndrome to contribute to the literature because we found it essential in the differential diagnosis with pneumothorax and the concomitant ectopic renal fusion anomaly.

\section{References}

1. Swyer PR, James GC. A case of unilateral pulmonary emphysema. Thorax. 1953 8:133-6.

2. Macleod WM. Abnormal transradiancy of one lung. Thorax. 1954;9:147-53.

3. Ödev K. Toraks Radyolojisi kitabı, Genişletilmiş ikinci baskı. Nobel Tip Kitapevleri. 2010;437-8

4. Sulaiman A, Cavaille A, Vaunois B, Tiffet O. Swyer-James-MacLeod syndrome; repeated chest drainages in a patient misdiagnosed with pneumothorax. Interact Cardiovasc Thorac Surg. 2009;8:482-4.

5. John BM. Letters to the editor. Swyer-James Macleod syndrome. Indian Pediatr. 2006;43:746-7.

6. Chalmers JH Jr. Swyer James syndrome. Semin Respir Infect. 1999;14 295-7.

7. Benzarti M, Jerray M, Mezghenni S, et al. Unilateral hyperlucent lung. Radiology. 1998;206:95-101.

8. Capela C, Gouveia P, Sousa M, et al. Adult diagnosis of Swyer-James-MacLeod syndrome: a case report. J Med Case Rep. 2011;5:2.

9. Yıldız F, Sever M, Kömür N, et al. Sağ Orta lob agenezisi ile Birlikte Olan Macleod Sendromu. Tur Toraks Der. 2010;11:87-9.

10. McNamara MF, McCurdy CM, Reed KL, et al. The relation between pulmonary hypoplasia and amniotic fluid volume: lessons learned from discordant urinary tract anomalies in monoamniotic twins. Obstet Gynecol. 1995 85(5 Pt 2):867-9.

11. Mehrizi A. Congenital malformation of the heart associated with congenital anomalies of the urinary tract: including a syndrome of ventricular septal defect pulmonary hypertension, mental retardation, and skeletal deformity. $J$ Pediatr. 1962;61:582-9.

\title{
Successful lung volume reduction surgery in an infant with emphysema after respiratory syncytial virus-induced obliterative bronchiolitis
}

\author{
Jun Yanagisawa, MD, ${ }^{\text {a }}$ Takeshi Shiraishi, MD, ${ }^{\mathrm{a}}$ Yuki Okamatsu, MD, ${ }^{\mathrm{b}}$ and Akinori Iwasaki, MD, ${ }^{\mathrm{a}}$ \\ Fukuoka, Japan
}

Lung volume reduction surgery (LVRS) was undertaken to improve respiratory function and clinical symptoms in a patient with severe emphysema. The procedure included a multiple wedge resection of the emphysematous lung, which resulted in an enhanced elastic recoil of the lung parenchyma followed by improved lung ventilation efficiency. Lung volume reduction surgery is indicated for adult patients with emphysema and offers clinical improvements in exercise tolerance, lung function, and

\footnotetext{
From the Department of General Thoracic, ${ }^{\text {a }}$ Breast and Pediatric Surgery, School of Medicine, Fukuoka, Japan; and the Department of Pediatrics, ${ }^{\mathrm{b}}$ Kurume University School of Medicine, Fukuoka, Japan.

Disclosures: Authors have nothing to disclose with regard to commercial support.

Received for publication May 30, 2012; revisions received Dec 5, 2012; accepted for publication Jan 17, 2013; available ahead of print Feb 18, 2013.

Address for reprints: Jun Yanagisawa, MD, Department of General Thoracic, Breast, and Pediatric Surgery, Fukuoka University School of Medicine, 7-45-1 Nanakuma,

Jonan-ku, Fukuoka 814-0180, Japan (E-mail: jyanagi@fukuoka-u.ac.jp).

J Thorac Cardiovasc Surg 2013;145:e47-9

$0022-5223 / \$ 36.00$

Copyright (C) 2013 by The American Association for Thoracic Surgery

http://dx.doi.org/10.1016/j.jtcvs.2013.01.037
}

quality of life; however, the effect of LVRS in infants is still unclear.

\section{CLINICAL SUMMARY}

An infant was healthy after an uneventful pregnancy and delivery until she was affected with respiratory syncytial virus-induced bronchiolitis at 4 months. Thereafter, she required repeated hospitalization because of subsequent respiratory infection. Chest radiographs showed progressive emphysematous changes in both lungs, and her respiratory condition deteriorated. The infant required frequent artificial ventilation support despite intensified medical therapy, and finally she was referred to be considered for surgical treatment, including LVRS, at the age of 1 year 9 months.

Chest computed tomography revealed ventral predominant diffuse emphysema in both lungs and herniation of the right middle lobe across the midline (Figure 1). The dorsal sides of the lungs developed complete atelectasis with traction stenosis of the bilateral lower lobe bronchus. The patient was intubated and on a ventilator at the time of 